\title{
Early norepinephrine decreases fluid and ventilatory requirements in pediatric vasodilatory septic shock
}

\author{
Suchitra Ranjit, Rajeswari Natraj, Sathish Kumar Kandath, Niranjan Kissoon', \\ Balasubramaniam Ramakrishnan ${ }^{2}$, Paul E. Marik ${ }^{3}$
}

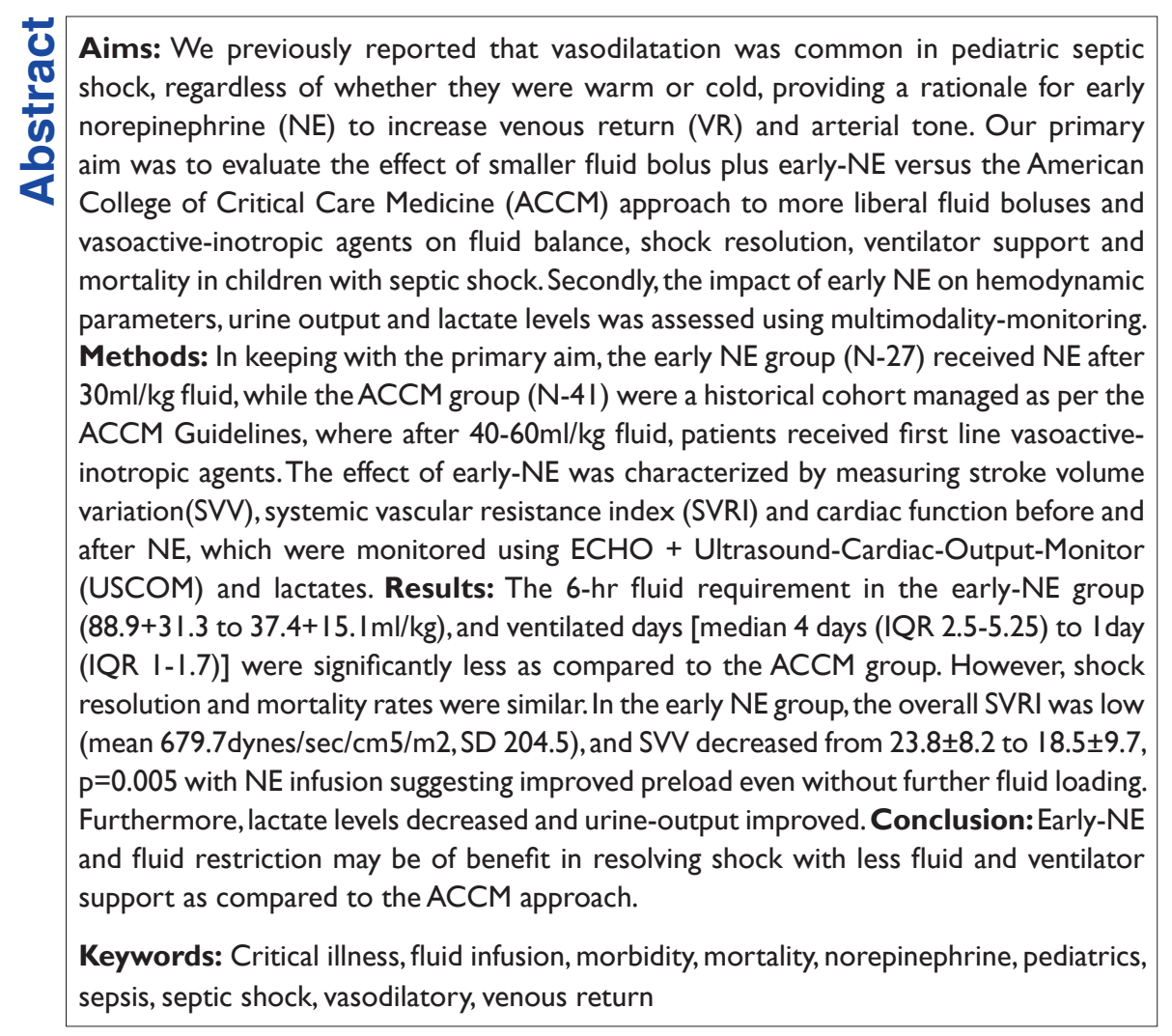

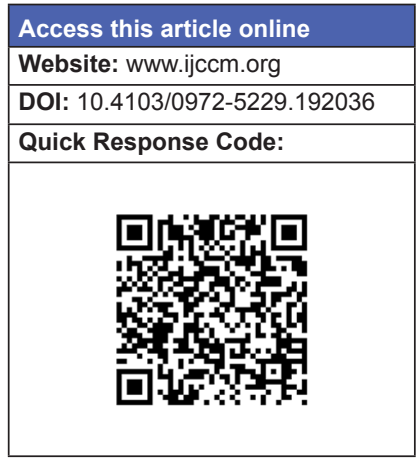

\section{Introduction and Aims}

We previously reported that vasodilation is a predominant feature in $85 \%$ of children in septic shock. ${ }^{[1,2]}$ Venodilatation leads to peripheral pooling of blood and

\section{From:}

Pediatric Intensive Care Unit, Apollo Children's Hospital, ${ }^{2}$ Department of Medical Education, Apollo Hospitals, Chennai, Tamil Nadu, India, ${ }^{1}$ Department of Pediatrics and Emergency Medicine, BC Children's Hospital, Sunny Hill Health Centre for Children, University of British Columbia, BC V6H 3V4,

Canada, ${ }^{3}$ Department of Pulmonary and Critical Care Medicine, Eastern Virginia Medical School, VA 23507, USA

\section{Correspondence:}

Dr. Suchitra Ranjit, Pediatric Intensive Care and Emergency Services, Apollo Children's Hospital, Greams Road, Chennai - 600 006, Tamil Nadu, India.

E-mail: suchitraranjit@yahoo.co.in relative hypovolemia which, compounded with arteriolar vasodilatation, exacerbates hypotension. ${ }^{[3,4]}$ While liberal fluids and vasoactive agents may be beneficial, overreliance on either may realize short-term gains but

This is an open access article distributed under the terms of the Creative Commons Attribution-NonCommercial-ShareAlike 3.0 License, which allows others to remix, tweak, and build upon the work non-commercially, as long as the author is credited and the new creations are licensed under the identical terms.

For reprints contact: reprints@ medknow.com

How to cite this article: Ranjit S, Natraj R, Kandath SK, Kissoon N, Ramakrishnan B, Marik PE. Early norepinephrine decreases fluid and ventilatory requirements in pediatric vasodilatory septic shock. Indian J Crit Care Med 2016;20:561-9. 
may increase morbidity. ${ }^{[5-8]}$ Liberal fluids pose greater risks in regions with limited ventilator capabilities. In view of the predominance of vasodilation in our cohort, we hypothesized that a combination of initial fluid bolus of $30 \mathrm{ml} / \mathrm{kg}$ plus moderate doses of norepinephrine (NE) $0.05-0.1 \mathrm{mcg} / \mathrm{kg} / \mathrm{min}$ (to improve arterial tone, restore cardiac-preload by its alpha-mediated venoconstriction, and provide modest inotropy) ${ }^{[3,4]}$ would reverse the disordered physiology while limiting positive fluid balance and need for ventilator support.

Our hypothesis is supported by reports in adults in whom vasodilatory septic shock is common and early NE improved preload and cardiac output (CO) without the need for large volume fluid boluses. ${ }^{[9-12]}$ We felt that the adult approach will be beneficial as compared to our previous approach which was based on the American College of Critical Care Medicine (ACCM) guidelines ${ }^{[13]}$ where shock refractory to at least $40-60 \mathrm{ml} / \mathrm{kg}$ of fluid was treated with the various inotrope-vasoactive agent(s) depending on the blood pressure (BP) and whether the extremities were cold or warm on clinical examination. ${ }^{[1]}$

Our study had two broad aims. First, we compared mortality, shock resolution, 6- and 24 h fluid balance, and duration of invasive ventilation between two groups, the prospective early-NE group versus the ACCM-cohort (comprising a previously published cohort who were managed as per the ACCM Guidelines). ${ }^{[1]}$

The second part compared pre- and post-NE hemodynamic parameters within the early-NE group using multimodal monitoring (MMM), specifically to assess fluid responsiveness (FR) as a surrogate of preload, cardiac function, and systemic vascular resistance (SVR); we also monitored for adverse effects including trends in urine flows and lactate levels.

\section{Methods}

\section{Setting}

All patients were treated in a 10-bed Pediatric Intensive Care Unit (PICU) of a tertiary referral children's hospital in Chennai, India, from April 2014 to October 2015.

The Institutional Ethics Committee approved the study protocol and since standard drugs and noninvasive cardiac monitoring were being used, the need for consent was waived.

\section{Patient selection}

For the early NE group, consecutive patients aged 1 month to 16 years with presumed infection and unresolved shock after $30 \mathrm{ml} / \mathrm{kg}$ fluid were included in the study. The methodology for the ACCM cohort was previously published. ${ }^{[1]}$ Shock was defined according to the ACCM/Pediatric Advanced Life Support (PALS) guidelines for defining severe sepsis. ${ }^{[13]}$

\section{Exclusions}

Our aim was to study effect of early NE on vasodilatory shock; hence, we excluded vasoconstricted shock (based on narrow pulse pressure, defined previously ${ }^{[1]}$ including dengue shock. We also excluded conditions where NE might cause worsening of circulatory status, i.e., cardiogenic shock, moribund patients including need for CPR. Other exclusions were premorbid conditions including malaria, malnutrition, anemia, and where extended MMM could not be performed within $4 \mathrm{~h}$ of shock recognition.

\section{Protocol for septic shock management}

- For both groups: At baseline, demographic and clinical data, hemodynamic status (extremity perfusion, mental status, heart rates, and $\mathrm{BP}$ ), and pediatric risk of mortality scores were entered in a standard datasheet. The first dose of broad-spectrum antibiotic(s) were administered within $1 \mathrm{~h}$ of shock recognition, and samples were drawn for relevant cultures, blood gas analyses, and lactate measurements

Intubation and ventilation were performed for

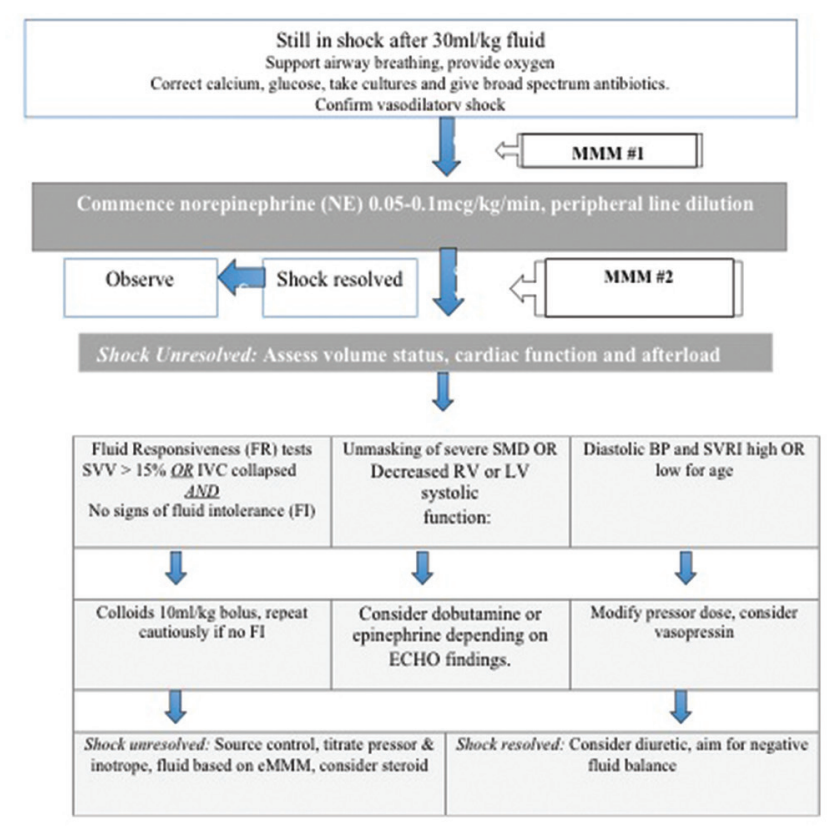

Figure Ia: Treatment protocol for limited fluid and early norepinephrine cohort. eMMM: Extended-multimodal-monitoring (physical examination, focused ECHO + USCOM); USCOM: Ultrasound cardiac output monitor; FI: Fluid intolerance (features of fluid overload or pulmonary edema); SVRI: Systemic vascular resistance index; IVC: Inferior vena cava; SV: Stroke-volume-variation 
Figure Ib: Hemodynamic treatment pathway for American College of Critical Care Medicine cohort based on multimodal monitoring in patients shock refractory to $40-60 \mathrm{ml} / \mathrm{kg}$ fluid

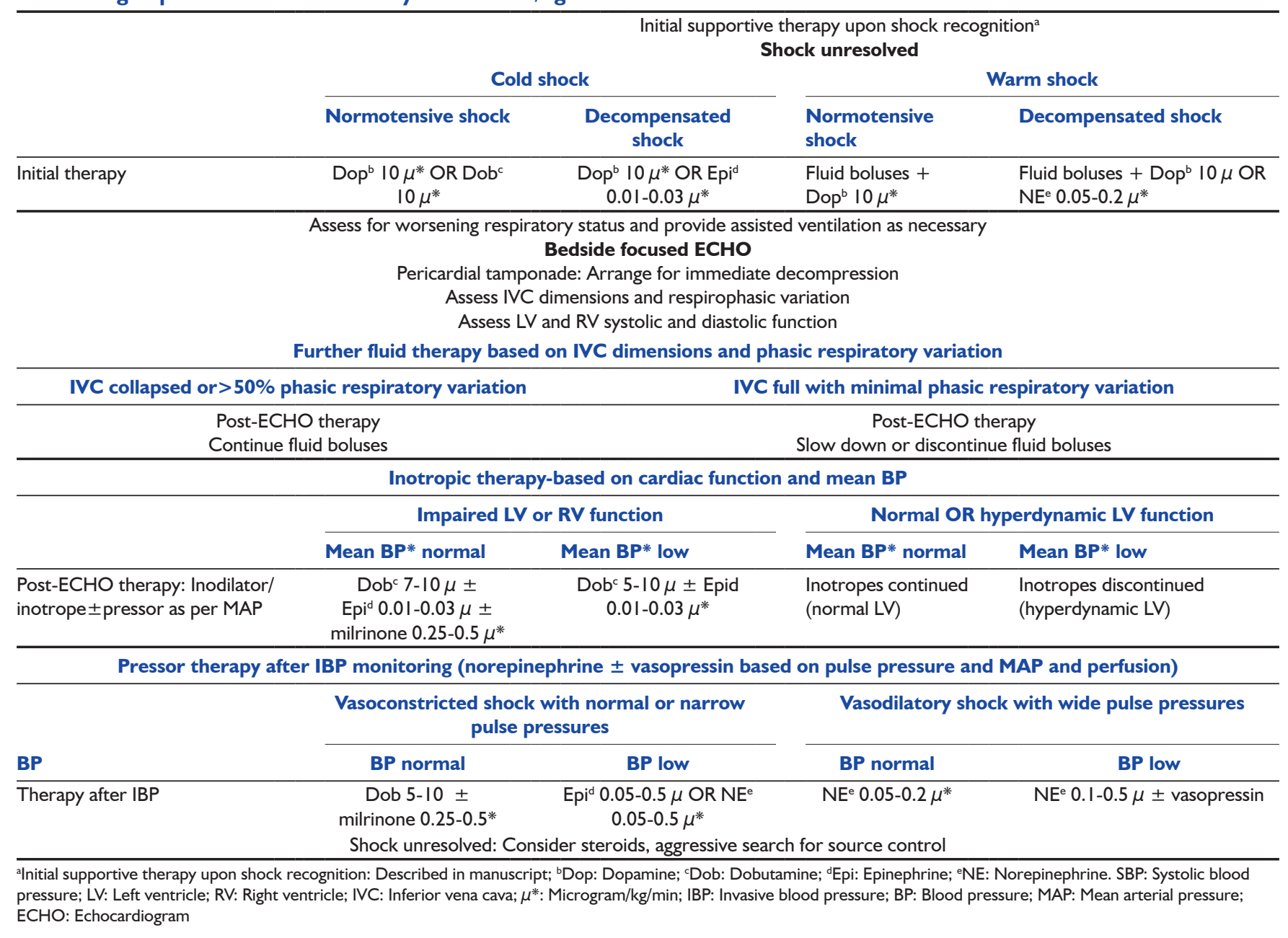

respiratory insufficiency or for unresolved shock despite $30-40 \mathrm{~mL} / \mathrm{kg}$ fluid and to facilitate the safe use of sedatives during invasive catheter placement. Patients were ventilated in volume-controlled mode with lung protective strategies (tidal volumes, 6-8 $\mathrm{mL} / \mathrm{kg}$ )

- For the early-norepinephrine group [Figure 1a]: One of the authors (SR, RN, and SKK) evaluated the patients with unresolved shock after $30 \mathrm{ml} / \mathrm{kg}$ fluid, and if there were no exclusions, NE was initiated at $0.05-0.1 \mathrm{mcg} / \mathrm{kg} / \mathrm{min}$ through a peripheral line. Ultrasound cardiac output monitor (USCOM) monitoring was also performed in addition to MMM. The time between the two consecutive measurements did not exceed $2 \mathrm{~h}$. Peripheral NE infusion was changed to central NE as soon as central access was secured. If shock was unresolved after initial fluid bolus plus $\mathrm{NE}$, further cardiovascular therapy (fluid, inotrope, or pressor) was directed by the findings of MMM

- For the ACCM cohort [Figure 1b]: Following early stabilization including point-of-care testing, first-hour antibiotics, and respiratory support, ${ }^{[1]}$ at least $40 \mathrm{ml} /$ $\mathrm{kg}$ fluids were infused, and inotropes-vasopressors were initiated. ${ }^{[1,13]} \mathrm{MMM}$ was performed in order offer customized cardiovascular therapy for those with unresolved shock.

\section{Multimodal-monitoring}

In both groups, patients with unresolved shock received MMM which included clinical assessment, invasive arterial monitoring, and focused echocardiography. Findings from MMM were used to guide further therapy in both groups. However, in the early-NE group, to study the impact of early NE on the circulation, all patients were additionally monitored using USCOM before and after NE infusion.

Authors (SR, RN, and SKK) were trained and certified in ICU sonology (basic + advanced) and also USCOM as per recommendations. ${ }^{[14]}$ Moreover, to minimize observer variability, the first author (SR), who had the 
most experience in both modalities, evaluated all images. Only those images that were satisfactory in terms of image quality and were accurate in interpretation were included in the study. During the USCOM, sinus rhythm was confirmed, spontaneous breathing was not permitted, and the tidal volumes were increased briefly up to $8 \mathrm{~mL} / \mathrm{kg}$ provided the plateau pressures did not exceed $30 \mathrm{~cm} \mathrm{H}_{2} \mathrm{O}$.

Techniques and normal values for USCOM variables are described in the USCOM manual. ${ }^{[15]}$

\section{Parameters studied by multimodal monitoring and ultrasound cardiac output monitor}

- Volume status: We used dynamic indices of FR as surrogates of cardiac preload. ${ }^{[16,17]}$ We considered the patient to be fluid responsive if the stroke volume variation (SVV) was $>15 \%$, based on pediatric studies ${ }^{[18]}$

- Cardiac function: Cardiac function was assessed by focused ECHO described previously ${ }^{[1]}$ and USCOM parameters (for early-NE group) including peak velocity and Smith-Madigan inotropy index (SMII) or inotropy index (INO). The SMII or INO index is calculated by the USCOM software and represents a rapid, accurate, loading-independent index to quantify myocardial contractility that is expressed in watts $/ \mathrm{m}^{2}{ }^{\left[{ }^{19]}\right.}$ We also monitored stroke volume index and cardiac index $(\mathrm{CI})^{[15,20]}$

- Afterload:Vasodilatory versus vasoconstricted shock was determined by pulse pressure and diastolic BP; ${ }^{[1]}$ SVR index (SVRI) was derived by the USCOM software ${ }^{[15]}$

- Physical examination: Physical examination was used to assess perfusion and lung mechanics before and after NE

- Tissue perfusion: We monitored lactate trends, and urine flows as surrogates of tissue perfusion.

\section{Data analysis}

In keeping with our study aims, two broad sets of analyses were performed:

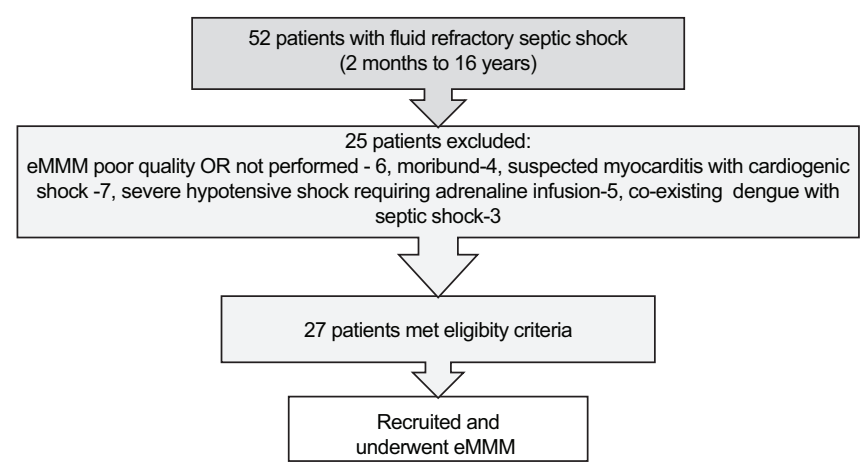

Figure 2: Recruitment and screening of study patients in early-norepinephrine group. eMMM: Extended multimodal monitoring
- Early NE versus ACCM cohort: Demographics and outcomes comparing fluid balance, ventilator support, PICU stay, and mortality

- "Before-after NE" intra-group analysis: We compared MMM findings pre- and post-NE to assess SVRI, SVV, and cardiac function among

Table I: Spectrum, microbiology, and type of infections in early norepinephrine group and the American College of Critical Care Medicine cohort

\begin{tabular}{|c|c|c|}
\hline & $\begin{array}{c}\text { Early NE } \\
\text { group }(n=27)\end{array}$ & $\begin{array}{c}\text { ACCM cohort } \\
(n=4 I)\end{array}$ \\
\hline \multicolumn{3}{|l|}{ Focus } \\
\hline \multirow[t]{2}{*}{ Pneumonia } & 11 & 20 \\
\hline & CAP; I0, VAP: I & CAP: I6, VAP: 4 \\
\hline CRBSI & 3 & 5 \\
\hline Abdominal/tgastrointestinal & 3 & 5 \\
\hline Skin, soft tissue including burns, bone & 6 & 4 \\
\hline Central nervous system & 4 & 4 \\
\hline Urine (pyelonephritis) & & 3 \\
\hline Microbiological culture positive cases & $18 / 27$ & $27 / 4 \mid$ \\
\hline Klebsiella & I & 4 \\
\hline Pseudomonas & & 5 \\
\hline Staphylococcus aureus & 5 (MRSA 2) & 4 (MRSA I) \\
\hline Streptococcus species & 3 & 4 \\
\hline Enterococcus & & $\mathrm{I}$ \\
\hline Proteus & & I \\
\hline Escherichia coli & 3 & 3 \\
\hline Acinetobacter & 2 & 2 \\
\hline Candida species & $\mathrm{I}$ & I \\
\hline Gram-negative rods & $\mathrm{I}$ & 1 \\
\hline Scrub typhus (ELISA) & 3 & I \\
\hline Hospital-acquired & II & 14 \\
\hline Community-acquired & 18 & 27 \\
\hline $\begin{array}{l}\text { Immunocompromised (recent/current } \\
\text { long-term steroid use, leukemia/ } \\
\text { postbone marrow transplant) }\end{array}$ & 4 & 6 \\
\hline Immunocompetent & 23 & 35 \\
\hline
\end{tabular}

MRSA: Methicillin-resistant Staphylococcus aureus; ELISA: Enzyme-linked immunosorbent assay; CRBSI: Catheter-related bloodstream infection; NE: Norepinephrine; ACCM: American College of Critical Care Medicine; VAP: Ventilator-associated pneumonia; CAP: Community-acquired pneumonia

Table 2: Demographics and outcomes between early norepinephrine group and American College of Critical Care Medicine cohort

\begin{tabular}{|c|c|c|c|}
\hline Variables & $\begin{array}{c}\text { Early NE } \\
\text { group }(n=27)\end{array}$ & $\begin{array}{c}\text { ACCM cohort } \\
(n=4 I)\end{array}$ & $P$ \\
\hline Weight (kg) & $24.3 \pm 19.04$ & $21.1 \pm 12.7$ & 0.856 \\
\hline PRISM & $19.9 \pm 7.8$ & $16.02 \pm 8.4$ & 0.06 \\
\hline $\begin{array}{l}\text { Number with hypotensive } \\
\text { shock at presentation (\%) }\end{array}$ & $19(70.4)$ & $20(48)$ & 0.09 \\
\hline $\begin{array}{l}0-6 \mathrm{~h} \text { fluid requirement } \\
(\mathrm{mL} / \mathrm{kg})\end{array}$ & $37.4 \pm 15.1$ & $88.9 \pm 31.3$ & $0.000 I^{*}$ \\
\hline $\begin{array}{l}\text { 24-h positive fluid balance } \\
(\% \mathrm{~mL} / \mathrm{kg})\end{array}$ & $4.8 \pm 4.5$ & $9.6 \pm 3.8$ & 0.000 I*** \\
\hline $\begin{array}{l}\text { Days on invasive ventilation, } \\
\text { median (survivors) }\end{array}$ & I (I-I.7) & $4(2.5-5.25)$ & $0.000 I^{*}$ \\
\hline Shock resolution & 26 & 39 & 1.00 \\
\hline $\begin{array}{l}\text { PICU days, median } \\
\text { (survivors) }\end{array}$ & $4(3-6)$ & $6(4-8)$ & $0.002 *$ \\
\hline Mortality (\%) & $3(11.1)$ & $4(9.8)$ & 1.000 \\
\hline
\end{tabular}

ACCM: American College of Critical Care Medicine; PRISM: Pediatric risk of mortality; PICU: Pediatric Intensive Care Unit 
"Responders" (partial/complete shock reversal) and

"Non-responders" (worsening of perfusion/shock).

\section{Statistical analysis}

The results are expressed as mean \pm standard deviation (SD) or median ( $25^{\text {th }}$ to $75^{\text {th }}$ percentile) as appropriate. Both sets of comparisons, Early NE versus ACCM cohort, and Before-after NE intra-group analysis were carried out using paired Student's $t$-test or the Wilcoxon signed-rank test as appropriate. $P<0.05$ was considered statistically significant.

\section{Results}

Fifty-five patients in septic shock were recognized in the ER or PICU, of which 27 patients with vasodilatory shock unresolved after $30 \mathrm{ml} / \mathrm{kg}$ were included in the study [Figure 2], and data for 41 patients described previously ${ }^{[1]}$ constituted the ACCM cohort.

\section{American College of Critical Care Medicine cohort versus early-norepinephrine group comparison}

There was no difference in baseline demographics or severity among the two groups [Tables 1 and 2]. Regarding early antibiotics, $27 / 27$ patients in the early NE group and $40 / 41$ patients in the ACCM cohort had received the first dose antibiotic(s) within the first hour of shock recognition. All patients received early fluid boluses and had appropriate specimens of cultures drawn, metabolic derangements corrected, and respiratory support initiated. All 27 in the early NE group and 38/41 in the ACCM cohort were intubated and ventilated principally to facilitate safe sedation for line placement or for respiratory insufficiency.

Table 1 shows the spectrum, microbiology, and type of infections among patients in both groups, and Table 2 compares demographics and outcomes between the early NE and ACCM cohort.

Fluid volumes, ventilator support, and Pediatric Intensive Care Unit stay

In addition to the limited $1^{\text {st }}$ hour fluid bolus, the 6-h fluid volumes, and 24-h positive fluid balance were significantly less in the early-NE group, and invasive ventilation and PICU days were also significantly lower [Table 2].

\section{Shock resolution and mortality}

Shock resolution was similar and there was no difference in mortality between the groups.
Comparison of hemodynamics before and after norepinephrine in early-norepinephrine group

Table $3 \mathrm{a}$ and $\mathrm{b}$ compares hemodynamic variables before and after NE among 22 patients who had partial or complete improvement (Responders), and 5 with worsened hemodynamic parameters (Non-responders).

a. SVRI changes: Of a total 27 patients, 17 had cold shock and 10 had warm shock; however, the overall SVRI was low (mean 679.7 dynes $/ \mathrm{s} / \mathrm{cm}^{5} / \mathrm{m}^{2}$, SD 204.5), this increased (mean 873.57 dynes $/ \mathrm{s} / \mathrm{cm}^{5} / \mathrm{m}^{2}$, SD 199) after NE infusion

b. Intravascular volume changes: The SVV declined significantly along with improved perfusion parameters [Table 2], and $19(70 \%)$ patients did not require any further fluid after the initial $30 \mathrm{ml} / \mathrm{kg}$. Additional small volume boluses were given to 8 patients with unresolved shock who were still fluid responsive with no features of fluid intolerance [Table $3 a$ and $b$ ]

c. Cardiac function response to NE depended on the intrinsic contractility. For instance, among 13 patients with hyperdynamic shock, the supranormal ejection fraction (EF) and CI values decreased to within normal range, and shock resolved.

Among 14 patients with septic myocardial dysfunction (SMD), the response to NE was variable. Four patients with mild systolic dysfunction resolved with NE alone, five with moderate SMD showed partial shock resolution and required additional inotropy (dobutamine/ epinephrine) for complete recovery.

Five patients manifested severely diminished cardiac function that only became apparent when afterload increased with NE (Non-responders, Table 3b). The unmasking of the severe underlying SMD in these five patients occurred within an hour of NE initiation and manifested as worsening perfusion and respiratory mechanics. The deterioration in cardiac function was confirmed by both ECHO and USCOM. Therapy in all five included rapid addition of more inotropes (epinephrine in four and dobutamine in one) while the NE dose was reduced in two patients and discontinued in three. Repeat MMM demonstrated improved cardiac function in all five patients, and four were discharged alive.

Lactate and urine output after early-norepinephrine Lactate trends improved in the responders [Table 3a]. Urine output increased on day- 1 in 24/27 patients and by day- 3 in another two patients.

Three patients had multiorgan failure (MOF) with acute kidney injury (AKI) requiring renal replacement 
Table 3a: Echocardiogram and ultrasound cardiac output monitor parameters before and after norepinephrine in 22 responders

\begin{tabular}{|c|c|c|c|c|}
\hline Hemodynamic variable & $\begin{array}{l}\text { ECHO, USCOM } \\
\text { and lactate values }\end{array}$ & Pre-NE $(n=22)$ & Post-NE $(n=22)$ & $P^{\#}$ \\
\hline Preload/fluid responsiveness & SVV & $23.79 \pm 8.2$ & $18.5 \pm 9.7$ & $0.005 *$ \\
\hline \multirow[t]{5}{*}{ Cardiac function } & Ejection fraction (\%) & $61.8 \pm 14.7$ & $64.6 \pm 11.09$ & $0.045 *$ \\
\hline & INO & $1.6 \pm 0.5$ & $1.7 \pm 0.5$ & 0.158 \\
\hline & $\mathrm{SVI}\left(\mathrm{mL} / \mathrm{m}^{2}\right)$ & $49.4 \pm 14.5$ & $48.9 \pm 14.3$ & 0.698 \\
\hline & $\mathrm{Cl}\left(\mathrm{L} / \mathrm{min} / \mathrm{m}^{2}\right)$ & $6.63 \pm 1.74$ & $6.3 \pm 1.68$ & 0.220 \\
\hline & $\operatorname{VPk}(\mathrm{m} / \mathrm{s})$ & $1.6 \pm 0.3$ & $1.6 \pm 0.3$ & 0.728 \\
\hline Afterload & SVRI (dynes $/ \mathrm{s} / \mathrm{cm}^{5} / \mathrm{m}^{2}$ ) & $682.9 \pm 224.8$ & $854.8 \pm 206.2$ & $0.000 I^{*}$ \\
\hline Perfusion & Lactate $(\mathrm{mmol} / \mathrm{L})$ & $4.9 \pm 4.5$ & $3.1 \pm 2.7$ & $0.006 *$ \\
\hline
\end{tabular}

*Significant at 5\%; \#Two-sided paired $t$-test. FTc: Flow time corrected; SVI: Stroke volume index; Cl: Cardiac index; SVRI: Systemic vascular resistance index; INO: Inotropy; SW: Stroke volume variation; VPk: Peak velocity; NE: Norepinephrine

Table 3b: Echocardiogram and ultrasound cardiac output monitor parameters before and after norepinephrine in five nonresponders with severe septic myocardial dysfunction

\begin{tabular}{|c|c|c|c|c|}
\hline Hemodynamic variable & $\begin{array}{l}\text { ECHO, USCOM } \\
\text { and lactate values }\end{array}$ & Pre-NE $(n=5)$ & Post-NE $(n=5)$ & $P^{\#}$ \\
\hline \multirow[t]{2}{*}{ Preload/fluid responsiveness } & SW & $22(18-31.5)$ & $18(1 \mathrm{I}-23.5)$ & 0.104 \\
\hline & FTc (ms) & $398(330.5-409.5)$ & $359(330-383.5)$ & 0.225 \\
\hline \multirow[t]{5}{*}{ Cardiac function } & Ejection fraction (\%) & $55(50-69.5)$ & $40(25-50)$ & $0.042 *$ \\
\hline & INO $(\mathrm{W})$ & $1.9(1.35-1.9)$ & I.2(0.79-I.5) & $0.043 *$ \\
\hline & $\mathrm{SVI}\left(\mathrm{mL} / \mathrm{m}^{2}\right)$ & $43(39-49)$ & $38(25.5-4 I)$ & 0.080 \\
\hline & $\mathrm{Cl}\left(\mathrm{L} / \mathrm{min} / \mathrm{m}^{2}\right)$ & $6.7(5.4-7.9)$ & $4.7(3.9-6.1)$ & 0.068 \\
\hline & $\operatorname{VPk}(\mathrm{m} / \mathrm{s})$ & $1.7(1.3-1.9)$ & $1.5(1.2-1.65)$ & 0.144 \\
\hline Afterload & SVRI (dynes $/ \mathrm{s} / \mathrm{cm}^{5} / \mathrm{m}^{2}$ ) & $672(605.5-723)$ & $957(820.5-1090)$ & $0.043 *$ \\
\hline Perfusion & Lactate $(\mathrm{mmol} / \mathrm{L}) \mathrm{s}$ & $3(1.5-4.5)$ & $5(3-9)$ & 0.223 \\
\hline
\end{tabular}

Median and IQR. *Significant at 5\% "Wilcoxon signed-rank test. FTc: Flow time corrected; SVI: Stroke volume index; Cl: Cardiac index; SVRI: Systemic vascular resistance index; INO: Inotropy index; SW: Stroke volume variation; VPk: Peak velocity; IQR: Interquartile range

therapy (RRT) on day-1, including peritoneal dialysis in one and continuous RRT in two patients. However, the renal function and urine output increased sufficiently such that RRT could be discontinued within $24-48 \mathrm{~h}$ in two patients, this included one patient who received NE plus additional vasopressin (VP) for severely depressed SVRI. The third patient continued to be anuric, azotemic, and could not be salvaged.

\section{Shock resolution and mortality}

There was no difference in shock resolution or mortality between the ACCM-cohort and Early-NE group, Table 2.

\section{Clinical trajectory in nonsurvivors (both groups)}

Of the three nonsurvivors in early-NE group, two with severe burn sepsis had rapid shock resolution with fluid and NE (plus inotropy in one) and were extubated and weaned off vasoactive-inotropes by day-2 and day-3, respectively. However, the patients suffered repeated episodes of bacteremia and MOF; both died 7 and 9 days later. The third nonsurvivor had severe community-acquired pneumonia and died at $28 \mathrm{~h}$ of admission of unresolved cold vasoplegic shock with very low SVRI $\left(<400\right.$ dynes $\left./ \mathrm{s} / \mathrm{cm}^{5} / \mathrm{m}^{2}\right)$ that failed to normalize even with high-dose NE, epinephrine, VP, and steroids.
In the ACCM cohort, four patients died, including two with unresolved shock and two with hematological malignancies and overwhelming pulmonary hemorrhage. ${ }^{[1]}$

\section{Discussion}

In this pilot feasibility study, we could demonstrate that, compared to the ACCM cohort, the limited fluid bolus and early-NE approach in pediatric vasodilatory shock was associated with decreased positive fluid balance and days on ventilation, with no change in shock resolution or mortality. Moreover, using USCOM before and after NE, we could show that the overall diminished SVRI increased, SVV decreased, and CI improved in the majority, and the treatment was associated with decreasing lactate levels and increasing urine output suggesting favorable physiologic effects.

We used the modest fluid boluses and early-NE in all 27 cases regardless of whether they were cold or warm, provided they were vasodilated (based on wide pulse pressures); this included 63\% with cold shock on clinical examination. This approach is supported by our previous reported experience where $85 \%$ of 48 septic shock patients were vasodilated with wide pulse pressure on 
invasive arterial pressure monitoring (including 14/21 with cold shock), corroborating other reports that clinical examination can be unreliable. ${ }^{[1,21]}$ The pathophysiological rationale of patients with vasodilatory shock presenting with cold shock is provided in excellent reviews. ${ }^{[3,4,22-25]}$

With regard to hemodynamic comparison pre- and post-NE, we studied the SVRI, FR using SVV, and cardiac function. We demonstrated that the SVRI after $30 \mathrm{ml} /$ $\mathrm{kg}$ fluid and before NE infusions was low, reconfirming that vasodilatory shock was predominant and justifying the early-NE-based approach.

Vasodilatory shock in children is not unique to our population and has been reported by others. For instance, Brierley and Peters reported that most patients with hospital-acquired infections had low SVRI-high CI shock and even among the community-acquired infections, $64 \%$ had low or normal SVRI, rather than the expected high values for the clinical picture of cold shock. ${ }^{[20]}$ Importantly, many patients were receiving significant doses of vasoactive agents, lending support to the assumption that the true incidence of vasodilatory shock may have been even higher before vasoactive therapy.

With respect to volume status in the early-NE group, the finding that the elevated SVV reduced after NE had important implications, suggesting that NE could mimic the effect of fluid loading by its venoconstrictor effects; moreover, perfusion also improved in 22/27 responders.

The effects of NE are not always salutary and in a given patient, the $\mathrm{CO}$ change is determined by the balance between the augmented preload effects, direct myocardial inotropicand arteriolar vasoconstrictor effects. ${ }^{[4,9]}$

Thus, in some patients, the greatly diminished myocardial reserve precludes an increase in $\mathrm{CO}$ and hence perfusion can be significantly reduced after fluids and NE administration. ${ }^{[4,26]}$ Indeed, in our study, while 4 with mild SMD improved with NE alone, 10 patients $(37 \%)$ with moderate to severe SMD required additional inotropic agents in addition to NE; among these 5 had significant decompensation and underlying severe SMD was "unmasked" (Non-responders); this could be detected by clinical examination and improved with additional inotropes and reduction/cessation of NE dose. That the severely diminished heart function can be effectively masked by the low afterload and revealed following NE-induced vasoconstriction has been previously reported. ${ }^{[26]}$
Dopamine is the initial vasoactive-inopressor agent suggested in the ACCM-PALS Guidelines, ${ }^{[13]}$ the Indian consensus, ${ }^{[27]}$ and in our previous studies. ${ }^{[1,2]}$ However, recently it's use has been questioned, ${ }^{[28]}$ with a higher incidence of hospital-acquired infections and mortality with dopamine-versus-epinephrine. ${ }^{[29]}$ Pure vasopressors such as VP may also not be ideal because it can cause reduction in $\mathrm{CO}$ and even death due to absent inotropy and increased afterload. ${ }^{[3,30]}$

Regarding the safety profile of NE in septic shock, despite concerns of renal ischemia, NE may in fact increase urine output and improve creatinine clearance in hyperdynamic septic shock ${ }^{[11,32]}$ and is the preferred agent for hypotensive vasodilated patients with AKI. ${ }^{[32]}$ In our cohort, the improved hemodynamics resulted in reduced lactate levels and improved urine output; the renal function improved sufficiently in two patients that RRT could be discontinued. In addition, the need for less fluid shortens the duration of mechanical ventilation; an important consideration in areas of the world where lack of ventilators can contribute to poor outcomes. ${ }^{[27,33]}$

Therefore, we suggest that NE may be the preferred first-line inopressor agent in pediatric vasodilatory septic shock after early limited volume bolus, given its ability to address the deranged pathophysiology by increasing preload, cardiac contractility, coronary perfusion and afterload, and without deterioration in urine flows or lactates. ${ }^{[4,9-12,28,32]}$

\section{Strengths}

Early NE and limited fluid boluses are both important departures from the standard ACCM Guideline, and to justify that this approach worked and was safe, we used extensive MMM with both ECHO and USCOM. MMM was logistically difficult, challenging, and never previously attempted; however, we designed the methodology acknowledging that each monitoring modality had unique strengths and limitations, and multimodal approach might best provide a more comprehensive hemodynamic picture, ${ }^{[34]}$ especially important when a different approach was attempted.

Further, we could document that NE could indeed mimic fluid loading and minimize the need for infused fluids, thus greatly decreasing time on ventilation and PICU days, and we believe that this finding has important implications that must be explored in larger studies. We also showed that lactate and urine output improved in the majority, thus allaying fears that NE might worsen ischemia. 


\section{Limitations and generalizability}

We used MMM principally to determine whether early-NE after limited volume resuscitation was safe and effective in pediatric septic shock and also to investigate the impact of NE on volume status, SVRI, and cardiac function. We do not at all suggest that MMM be incorporated in the early-NE algorithm as this will not be generalizable or even practical. However, while early-NE is beneficial in the majority with pediatric vasodilatory shock, in the event that the patient fails to improve or worsens, some form of hemodynamic monitoring depending on local expertise is important to help guide further cardiovascular therapy (fluid, inotrope or pressor).

\section{Conclusions and Clinical Implications of Our Study}

In a child with septic shock, the traditional order of therapy is liberal volume loading followed by inotrope-vasoactive infusions dictated by physical examination. We suggest that NE may be considered as a first-choice inopressor after limited fluids in vasodilatory shock (based on wide pulse pressures), as this approach may decrease the volume of fluids needed for resuscitation and the time on ventilator support. Careful bedside monitoring is emphasized to detect deterioration and initiate appropriate inotrope therapy for severely impaired cardiac contractility that may be unmasked with NE.

\section{Financial support and sponsorship Nil.}

\section{Conflicts of interest}

There are no conflicts of interest.

\section{References}

1. Ranjit S, Aram G, Kissoon N, Ali MK, Natraj R, Shresti S, et al. Multimodal monitoring for hemodynamic categorization and management of pediatric septic shock: A pilot observational study. Pediatr Crit Care Med 2014;15:e17-26.

2. Ranjit S, Kissoon N. Bedside echocardiography is useful in assessing children with fluid and inotrope resistant septic shock. Indian J Crit Care Med 2013;17:224-30.

3. Funk DJ, Jacobsohn E, Kumar A. The role of venous return in critical illness and shock-Part I: Physiology. Crit Care Med 2013;41:255-62.

4. Funk DJ, Jacobsohn E, Kumar A. Role of the venous return in critical illness and shock: Part II-shock and mechanical ventilation. Crit Care Med 2013;41:573-9.

5. Foland FA, Fortenberry JD, Warshaw BL, Naipaul A, Jefferson LS, Loftis LL. Fluid overload before continuous hemofiltration and survival in critically ill children; a retrospective analysis. Crit Care Med 2004;32:1771-6.

6. Sinitsky L, Walls D, Nadel S, Inwald DP. Fluid overload at 48 hours is associated with respiratory morbidity but not mortality in a general PICU: Retrospective cohort study. Pediatr Crit Care Med
2015;16:205-9.

7. Arikan AA, Zappitelli M, Goldstein SL, Naipaul A, Jefferson LS, Loftis LL. Fluid overload is associated with impaired oxygenation and morbidity in critically ill children. Pediatr Crit Care Med 2012;13:253-8.

8. Dellinger RP, Levy MM, Rhodes A, Annane D, Gerlach H, Opal SM, et al. Surviving sepsis campaign: International guidelines for management of severe sepsis and septic shock, 2012. Intensive Care Med 2013;39:165-228.

9. Maas JJ, Geerts BF, van den Berg PC, Pinsky MR, Jansen JR. Assessment of venous return curve and mean systemic filling pressure in postoperative cardiac surgery patients. Crit Care Med 2009;37:912-8.

10. Monnet X, Jabot J, Maizel J, Richard C, Teboul JL. Norepinephrine increases cardiac preload and reduces preload dependency assessed by passive leg raising in septic shock patients. Crit Care Med 2011;39:689-94.

11. Persichini R, Silva S, Teboul JL, Jozwiak M, Chemla D, Richard C, et al. Effects of norepinephrine on mean systemic pressure and venous return in human septic shock. Crit Care Med 2012;40:3146-53.

12. Hamzaoui O, Georger JF, Monnet X, Ksouri H, Maizel J, Richard C, et al. Early administration of norepinephrine increases cardiac preload and cardiac output in septic patients with life-threatening hypotension. Crit Care 2010;14:R142.

13. Brierley J, Carcillo JA, Choong K, Cornell T, Decaen A, Deymann A, et al. Clinical practice parameters for hemodynamic support of pediatric and neonatal septic shock: 2007 update from the American College of Critical Care Medicine. Crit Care Med 2009;37:666-88.

14. Dey I, Sprivulis P. Emergency physicians can reliably assess emergency department patient cardiac output using the USCOM continuous wave Doppler cardiac output monitor. Emerg Med Australas 2005;17:193-9.

15. The USCOM and Haemodynamies. Available from: http://www. learnhemodynamics.com/The_USCOM_and_Haemodynamics. pdf. [Last accessed on $2016 \mathrm{Feb} \overline{1} 3$ ]

16. Marik PE, Baram M, Vahid B. Does central venous pressure predict fluid responsiveness? A systematic review of the literature and the tale of seven mares. Chest 2008;134:172-8.

17. Marik PE, Lemson J. Fluid responsiveness: An evolution of our understanding. Br J Anaesth 2014;112:617-20.

18. Vergnaud E, Vidal C, Verchère J, Miatello J, Meyer P, Carli P, et al. Stroke volume variation and indexed stroke volume measured using bioreactance predict fluid responsiveness in postoperative children. $\mathrm{Br}$ J Anaesth 2015;114:103-9.

19. Smith BE, Madigan VM. Non-invasive method for rapid bedside estimation of inotropy: Theory and preliminary clinical validation. $\mathrm{Br}$ J Anaesth 2013;111:580-8.

20. Brierley J, Peters MJ. Distinct hemodynamic patterns of septic shock at presentation to pediatric intensive care. Pediatrics 2008;122:752-9.

21. Tibby SM, Hatherill M, Marsh MJ, Murdoch IA. Clinicians' abilities to estimate cardiac index in ventilated children and infants. Arch Dis Child 1997;77:516-8.

22. Hunter JD, Doddi M. Sepsis and the heart. Br J Anaesth 2010;104:3-11

23. Merx MW, Weber C. Sepsis and the heart. Circulation 2007;116:793-802.

24. Kumar A, Haery C, Parrillo JE. Myocardial dysfunction in septic shock: Part I. Clinical manifestation of cardiovascular dysfunction. J Cardiothorac Vase Anesth 2001;15:364-76.

25. Rabuel C, Mebazaa A. Septic shock: A heart story since the $1960 \mathrm{~s}$. Intensive Care Med 2006;32:799-807.

26. Vieillard-Baron A. Septic cardiomyopathy. Ann Intensive Care 2011;1:6.

27. Khilnani P, Singhi S, Lodha R, Santhanam I, Sachdev A, Chugh K, et al. Pediatric sepsis guidelines: Summary for resource-limited countries. Indian J Crit Care Med 2010;14:41-52.

28. De Backer D, Aldecoa C, Njimi H, Vincent JL. Dopamine versus norepinephrine in the treatment of septic shock: A meta-analysis. Crit Care Med 2012;40:725-30.

29. Ventura AM, Shieh HH, Bousso A, Góes PF, Fernandes I, de Souza DC, et al. Double-blind prospective randomized controlled trial of dopamine versus epinephrine as first-line vasoactive drugs in pediatric septic shock. Crit Care Med 2015;43:2292-302.

30. Choong K, Bohn D, Fraser DD, Gaboury I, Hutchison JS, Joffe AR, et al. 
Vasopressin in pediatric vasodilatory shock: A multicenter randomized controlled trial. Am J Respir Crit Care Med 2009;180:632-9.

31. Redl-Wenzl EM, Armbruster C, Edelmann G, Fischl E, Kolacny M, Wechsler-Fördös A, et al. The effects of norepinephrine on hemodynamics and renal function in severe septic shock states. Intensive Care Med 1993;19:151-4.

32. Bellomo R, Wan L, May C. Vasoactive drugs and acute kidney injury.
Crit Care Med 2008;36 4 Suppl:S179-86.

33. Santhanam I, Sangareddi S, Venkataraman S, Kissoon N, Thiruvengadamudayan V, Kasthuri RK. A prospective randomized controlled study of two fluid regimens in the initial management of septic shock in the emergency department. Pediatr Emerg Care 2008;24:647-55.

34. Beale R. Echoes of the past? Crit Care Med 2008;36:1950-1. 